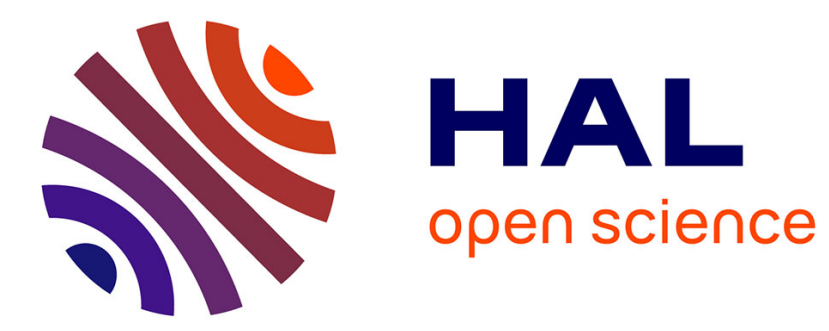

\title{
The temperature profile in weakly absorbing materials during irradiation
}

L. Aamodt, J. Murphy

\section{To cite this version:}

L. Aamodt, J. Murphy. The temperature profile in weakly absorbing materials during irradiation. Journal de Physique IV Proceedings, 1994, 04 (C7), pp.C7-103-C7-106. 10.1051/jp4:1994726 jpa00253254

\section{HAL Id: jpa-00253254 https://hal.science/jpa-00253254}

Submitted on 1 Jan 1994

HAL is a multi-disciplinary open access archive for the deposit and dissemination of scientific research documents, whether they are published or not. The documents may come from teaching and research institutions in France or abroad, or from public or private research centers.
L'archive ouverte pluridisciplinaire HAL, est destinée au dépôt et à la diffusion de documents scientifiques de niveau recherche, publiés ou non, émanant des établissements d'enseignement et de recherche français ou étrangers, des laboratoires publics ou privés. 


\title{
The temperature profile in weakly absorbing materials during irradiation
}

\author{
L.C. Aamodt and J.C. Murphy \\ The Milton S. Eisenhower Research Center, The John Hopkins University, Applied Physics Laboratory, \\ Johns Hopkins Road, Laurel, MD 20723-6099, U.S.A.
}

\begin{abstract}
Irradiated materials that are weakly absorbing are heated by both diffusive and direct heating. This creates various internal heating patterns and introduces the possibility of developing hot spots in the specimen that are not detected by surface monitoring. These systems are investigated for a single instantaneous radiation pulse and for a chain of such pulses. Characteristic times are identified that describe various regimes in the temporal-spatial heating pattern in the specimen.
\end{abstract}

Heat generation in a semi-transparent material (or a material subject to penetrating radiation) is a composite of diffusive heat flow and direct sub-surface heating. This situation arises in a variety of biological procedures where the specimen (or patient) is subjected to $\mathrm{x}$-ray or microwave irradiation. Of importance in such measurements, especially in vivo measurements, is whether localized internal hot spots are produced which might not be detected by monitoring the surface temperature. Such hot-spots could endanger the specimen (subject) being tested or cause a misinterpretation of experimental results.

To explore this possibility, a simple one-dimensional case is considered where a uniform, semiinfinite, planar specimen is heated by broad-beam radiation. To simulate either a defect, or a localized semi-opaque constituent, it is assumed that an ultra thin, planar, layer of a highly absorbing material is located at an arbitrary depth in the weakly absorbing specimen. Furthermore, to simulate some biological systems, the specimen bulk is assumed to contain a spatial, uniformly-distributed, heat sink which removes heat at a specified rate depending upon the localized temperature differential between the specimen and the heat sink. This could be considered to simulate a very elementary circulatory system. For simplicity the thermal parameters of the ultra thin defect are assumed to be essentially the same as the thermal parameters of the bulk. This emphasizes the conflict between diffusive and radiation heating and avoids the complexity of heat trapping and multilayer complications. To obtain an analytical solution, it is assumed that there is no significant heat loss at the specimen surface.

Under these conditions, heat flow in the specimen can be viewed as a competition between three distinct heating/cooling sources: heat flowing into and out of a specific region via diffusive heating, direct heating by the radiation, and heat removed from the thermal system by the heat sink. As would be expected, the internal temperature pattern in the postulated system is more complicated than the simple temperature patterns encountered in opaque materials where heating is by surface absorption followed by simple diffusive heat flow into the material.

In the postulated thermal system, temperature varies with depth and time and is dependant on the system's thermal parameters, on radiation parameters and on the depth, $z_{0}$, of the highly absorbing defect (or constituent). We view the problem in the time domain for an ultra short radiation pulse (considered to be instantaneous) as well as a chain of such pulses.

The temporal-spatial features of the system's thermal response to the radiation pulse are governed (or characterized) by three parameters, $t_{c}, t_{h s}$, and $\tau\left(z_{0}\right)$, where $t_{\mathrm{hs}}$ is the reciprocal of the rate of heat loss to the heat-sink; $t_{c}=1 /\left(\beta^{2} \alpha\right)$ is the natural time unit for the thermal system; and $\tau\left(z_{0}\right)=z_{0}^{2} /(4 \alpha)$ is the transit time for heat to diffuse from the specimen surface to the defect. Here $\alpha$ is the thermal 
diffusivity of the specimen, and $\beta$ is the radiation absorption coefficient. In addition, the magnitude of the thermal response is determined by the radiation density, the duration of the radiation pulse, the crosssectional area of the pulse, and the specimen's thermal effusivity. And, for a chain of pulses, on the repetition rate (or alternately, $\tau_{\mathrm{p}}$, the time interval between pulses).

It is convenient to define a normalized time, $t_{n}=t / t_{c}$. This allows the system's thermal response to the heating pulse to be described by universal curves. Depth in the specimen can also be designated temporally by defining various transit times, $\tau(\chi)=\chi 2 /(4 \alpha)$ where $\tau(\chi)$ is the time that it takes for heat to diffuse through a distance, $\chi$. For each depth, $z$, there are three distances of interest: the depth, $z$ (measured from the surface), $z-z_{0}$, the distance between the defect and depth $z$, and $z+z_{0}$, the distance from the defect to the surface and then back to the depth, $z$. A transit time can be defined for each of these distances.

The ratios of the various characteristic times, $t_{c}, t_{h c}$, and $\tau\left(z_{0}\right)$ establishes the character or nature of the thermal system's response to a radiation pulse, and the ratios, $t_{n}=t / t_{c}$ and $\tau(z) / \tau\left(z_{0}\right)$ determine the regime in which a heating pulse is operating at a particular depth, $z$, and time, $t$.

The ratio $t_{h s} / t_{c}$ determines the depth to which a heat pulse can penetrate before heat is stripped from the system by loss to the heat sink. Diffusive-heat-loss and loss to the heat sink are complementary processes both removing heat from a particular point (and, for diffusive heating, bringing heat to that point). The heat sink removes heat from the system completely while diffusive heat flow allows the heating pulse to penetrate deeper into the specimen. Consequently, for $t_{h s}<<t_{c}$, the subsurface defect is heated by direct radiation only while for $t_{h s}>>t_{c}$ it is heated by both diffusive heating and by direct radiation heating. The cross-over between these two regimes depends upon the distance that the defect is from the surface, i.e., on the transit time, $\tau(\mathrm{z}) / \tau\left(\mathrm{z}_{0}\right)$.

For a chain of pulses, the internal temperature also depends upon the repetition-rate. If the combined diffusive and heat-sink loss essentially dissipate the heat in a pulse before the next pulse arrives, each pulse acts separately, otherwise the temperature builds up eventually leveling off as heatsink losses rise to counterbalance the heat input.

Some of effects described above are shown in the following figures. Only a few cases can be shown here, the remainder must await later publication. In all figures, the defect is assumed to absorb $5 \%$ of the radiation reaching it, the thermal properties of the specimen are those of water, and the radiation intensity is equivalent to a radiation pulse of 10 megawatts $/ \mathrm{cm}^{2}$ over an area of $10 \mathrm{~cm}^{2}$ and a duration of 1 microsec. For all figures, the defect is located $1 \mathrm{~cm}$ below the surface. The other parameters are indicated in the text or in figure captions.

Figure 1 shows the time development of the temperature at a depth of $9.5 \mathrm{~mm}$ for a sequence of pulses. The solid curve shows the temperature buildup when the combined heat-sink and diffusive loss drains most of the heat away between pulses $\left(t_{h c}=0.1 \mathrm{sec}\right)$ while the dotted curve is the case where little heat is lost between pulses $\left(t_{h c}=1 \mathrm{sec}\right)$. As expected, when little heat is lost, the pattern is essentially a staircase of temperatures where each successive step is smaller, eventually reaching a steady state. By contrast, when more heat is lost between pulses, the pattern is a series of decaying pulses with a slowly increasing base line (which reaches a (lower) steady state). If there is a significant surface heat loss (or in the practical case where the radiation area is limited with a consequent lateral heat flow), the stair case pattern may not be realized. This depends upon the thermal mismatch at the surface and the rate of heat loss to the heat sink.

If the specimen is sufficiently absorbing, the radiation reaching the defect is essentially zero so the temperature profile is just that of a semi-infinite, exponentially absorbing, material. If the loss to the heat sink is much more rapid than the transit time to the defect, little diffusive heat reaches the defect and it is heated exclusively by direct radiation. If $\beta$ is large and thc is small, the presence of the defect has no effect on the temperature profile.

Figure 2 shows a (theoretical) family of temperature profiles recorded at 5 pulses intervals during a sequence of pulses, the profile being frozen at the initiation of the indicated pulse. Several features can be seen. The decreasing temperature gap between successive members of the family shows the approach to a steady state. The sub-surface peak shows the creation of an internal hot spot. For this particular case, the internal peak is persistently higher than the corresponding surface temperature for all pulses in the chain, but, in general, the relative magnitude of the temperature of the hot spot and the surface temperature is strongly sensitive to $t_{c}$ and $t_{h c}$, and can change as the number of pulses in the pulse chain increases. 


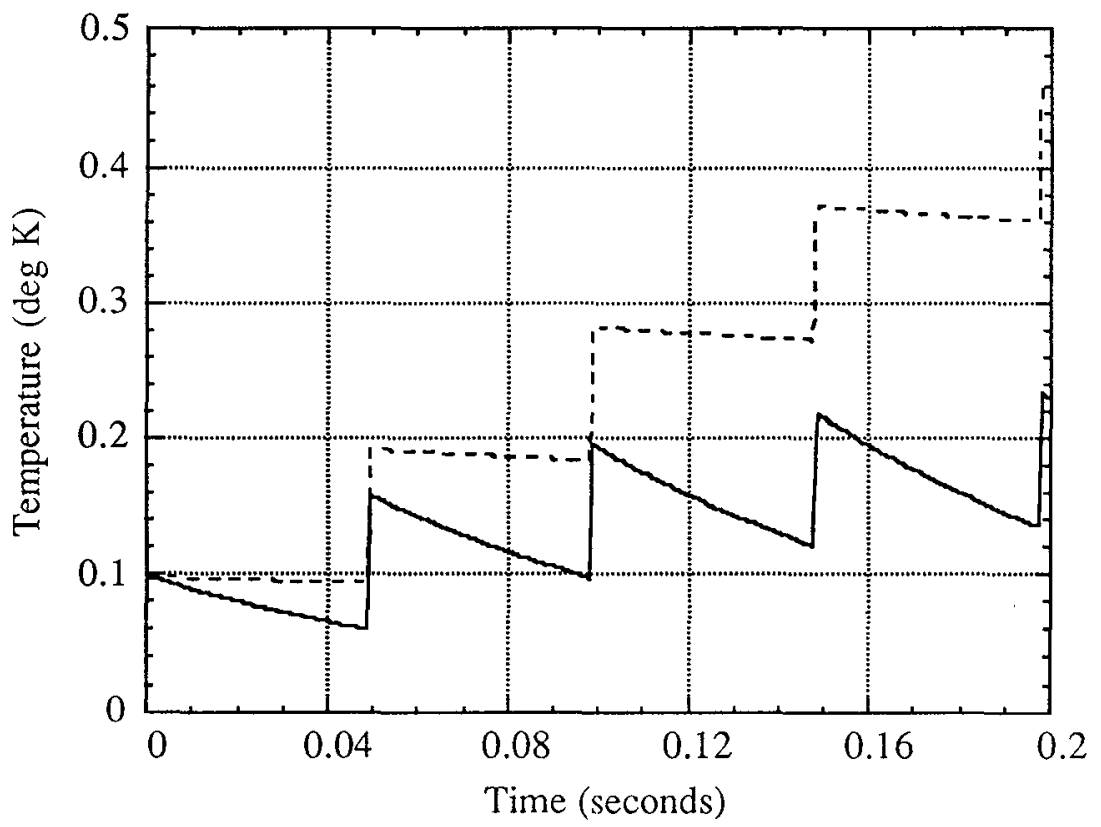

Figure1: Temperature buildup during a sequence of pulses. $\left[\tau_{p}=50 \mathrm{msec} ; \beta=1 \mathrm{~cm}^{-1} ; z_{0}=9.5 \mathrm{~mm}\right.$; $t_{h c}=0.1 \mathrm{sec}($ solid $)=1 \mathrm{sec}$ (dashed).]

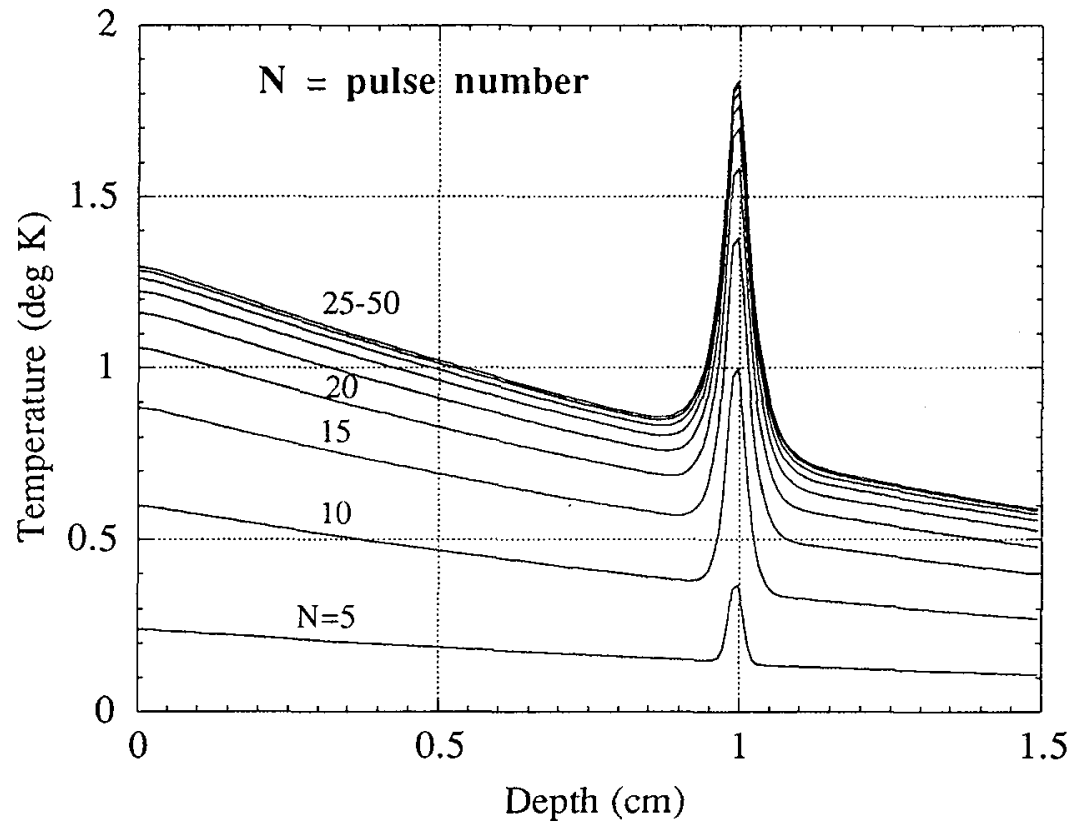

Figure 2: Temperature profiles recorded at equal time intervals ( 5 pulses) during a sequence of pulses. $\left[\tau_{\mathrm{p}}=50 \mathrm{msec} ; \beta=0.5 \mathrm{~cm}-1 ; \mathrm{z}_{\mathrm{O}}=9.5 \mathrm{~mm} ; \mathrm{thc}_{\mathrm{hc}}=0.5 \mathrm{sec}.\right]$ 
Figure 3 is similar to figure 2 , but is plotted using normalized coordinates with 10 pulse intervals between profiles. Each profile is plotted over a range zero to $1.5 \mathrm{x}$ the defect depth, which for this case is $1.5 \mathrm{~cm}$. For this case as the number of pulses increase, the temperature of the hot spot initially exceeds the corresponding surface temperature but later is less than the surface temperature.

In these calculations several assumptions have been made. The system is assumed to be semiinfinite which implies that the heating pulse has become insignificant (as one moves deeper into the specimen) before a thermal barrier is encountered. As a consequence the temperature continues to decays below the defect as shown in figure 3 . If a thermal barrier had been met, the thermal problem would have become a multilayer problem involving a series of thermal reflections.

It was also assumed that negligible heat is lost at the specimen surface. Should the thermal conductivity of the specimen approach that of the media above the specimen's surface, or if the surface temperature is very large, a correction must be made that depends on the ratio of the gas/bulk effusivities at the surface. The temporal pattern then depends upon the frequency dependent thermal mismatch at the surface.

This work was supported by the U.S. Navy Space and Warfare Command under contract N00039-91-C-001.

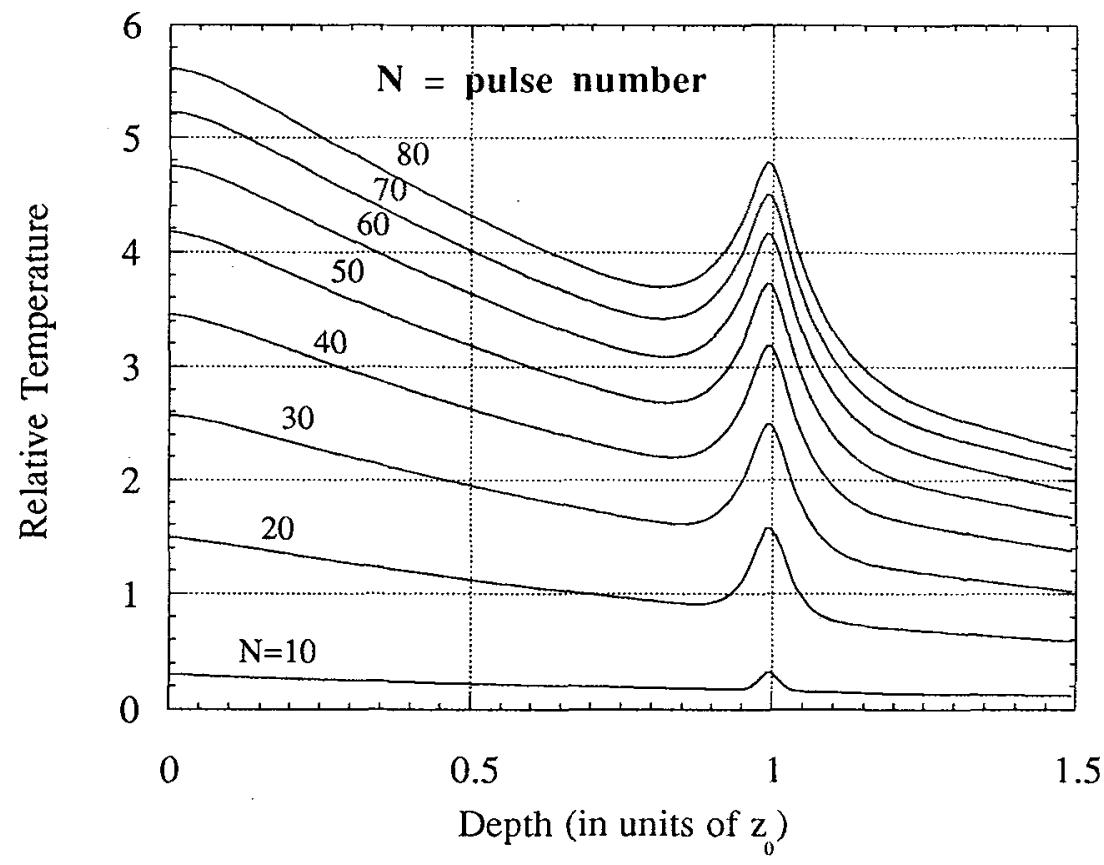

Figure 3: Temperature profiles recorded at equal time intervals (10 pulses) during a sequence of pulses plotted using normalized coordinates. $\left[\mathrm{t}_{\mathrm{c}}=2000 \mathrm{sec} ; \tau_{\mathrm{p}}=0.00005 \mathrm{t}_{\mathrm{c}} ; \mathrm{t}_{\mathrm{hc}}=0.0025 \mathrm{t}_{\mathrm{c}} ; \tau\left(\mathrm{z}_{\mathrm{o}}\right)=\right.$ $0.09 \mathrm{t}_{\mathrm{c}}$ ] 